\title{
Decreased Bone Mineral Density in Patients Submitted to Kidney Transplantation Is Related to Age, Body Mass Index, Time on Dialysis, and Hyperparathyroidism
}

\author{
Miguel Madeira, ${ }^{1,2}$ Mário Sérgio Zen, ${ }^{2}$ Paulo Gustavo Sampaio Lacativa, ${ }^{3}$ \\ Carolina Hammes Torres, ${ }^{2}$ Ana Paula Pires Lázaro, ${ }^{2}$ Renato Torres Gonçalves, ${ }^{4}$ \\ Laura Maria Carvalho de Mendonça, ${ }^{5}$ and Maria Lucia Fleiuss de Farias ${ }^{2}$ \\ ${ }^{1}$ Serviço de Endocrinologia, HUCFF, Rua Professor Rodolpho Paulo Rocco 255, $9^{\circ}$ andar, Edifício do HUCFF, \\ Cidade Universitária, Ilha do Fundão, 21941-913 Rio de Janeiro, RJ, Brazil \\ ${ }^{2}$ Division of Endocrinology, Department of Internal Medicine, Hospital Universitário Clementino Fraga Filho, \\ Universidade Federal do Rio de Janeiro, Rio de Janeiro, Brazil \\ ${ }^{3}$ Department of Internal Medicine, Hospital Universitário Pedro Ernesto, Universidade Estadual do Rio de Janeiro, \\ Rio de Janeiro, Brazil \\ ${ }^{4}$ Division of Nephrology, Department of Internal Medicine, Hospital Universitário Clementino Fraga Filho, \\ Universidade Federal do Rio de Janeiro, Rio de Janeiro, Brazil \\ ${ }^{5}$ Division of Rheumatology, Department of Internal Medicine, Hospital Universitário Clementino Fraga Filho, \\ Universidade Federal do Rio de Janeiro, Rio de Janeiro, Brazil
}

Correspondence should be addressed to Miguel Madeira; migmadeira@gmail.com

Received 22 April 2014; Revised 15 July 2014; Accepted 29 July 2014; Published 18 August 2014

Academic Editor: Massimiliano Ruscica

Copyright (c) 2014 Miguel Madeira et al. This is an open access article distributed under the Creative Commons Attribution License, which permits unrestricted use, distribution, and reproduction in any medium, provided the original work is properly cited.

Background. Renal transplantation (Tx) influences bone mineral density (BMD) by several mechanisms. The main objective of this study was to correlate BMD and risk factors associated with bone loss in patients submitted to kidney Tx. Methods. We evaluated 88 individuals after renal Tx (median time $=31.5$ months since Tx). All of them sustained glomerular filtration rate $\geq 60 \mathrm{~mL} / \mathrm{min} / 1.73 \mathrm{~m}^{2}$. BMD was measured by dual-energy X-ray absorptiometry (DXA, Prodigy-GE). Calcium, phosphate, albumin, creatinine, and intact parathormone (PTH) were measured at the same time. All statistical tests were two-sided and $P$ value less than 0.05 were accepted as significant for all analyses in this study. Results. Serum PTH was raised in $42 \%$ patients, but corrected calcium was normal in 83 patients. No fragility fracture was reported, but the overall prevalence of osteoporosis was $27.6 \%$ and lower than expected BMD ( $Z$-score $\leq-2.0 \mathrm{SD}$ ) was observed in 28.4\%. Patients with lower than expected BMD had higher PTH levels. Conclusions. Older age, lower body mass index (BMI), longer time on dialysis, and elevated PTH levels were identified as the main factors associated with lower BMD.

\section{Introduction}

Chronic kidney disease is caused by several conditions and has become a prevalent comorbidity. Renal transplantation (Tx) is the treatment of choice for most patients with endstage renal disease (ESRD) [1]. Advances in immunosuppressive agents and transplant techniques during the last decades have led to improved long-term graft and patient survival. This fact resulted in both increases in transplant numbers and an increased recognition of previously neglected longterm complications of Tx, such as osteoporosis and fractures. Osteoporosis is prevalent in more than half of solid organ recipients and vertebral fractures are found in almost a third of patients [2].

Particularly during the early post-Tx period, kidney recipients experience a rapid loss of bone mass [3]. Rates of bone loss are greatest during the first 6-18 months after renal Tx and range from 4 to $9 \%$ at the spine and 5 to $8 \%$ at the 
TABLE 1: Daily pharmacological doses of posttransplantation immunosuppressive treatment of the 88 patients evaluated.

\begin{tabular}{|c|c|c|}
\hline & Initial doses & Maintenance doses \\
\hline Prednisone & $0.5 \mathrm{mg} / \mathrm{Kg} /$ day $(30-50 \mathrm{mg} /$ day) for up to 90 days & $5-7.5 \mathrm{mg} /$ day \\
\hline Mycophenolate mofetil & $500 \mathrm{mg} \mathrm{3-4} \mathrm{times/day}$ & $500 \mathrm{mg} 2-3$ times/day \\
\hline Tacrolimus & $0.15-0.2 \mathrm{ng} / \mathrm{kg} /$ day to obtain serum levels of $10-15 \mathrm{ng} / \mathrm{mL}$ (day 1 ) & Serum levels $3-7 \mathrm{ng} / \mathrm{mL}$ (4th day on) \\
\hline
\end{tabular}

hip [4]. Different factors have been associated to this bone disease. Chronic kidney disease-mineral and bone disorder (CKD-MBD) begins during the early stages of the disease and usually worsens during dialysis. Both pretransplantation bone disease and immunosuppressive therapy result in rapid bone loss and increased fracture rates $[4,5]$. It is expected that parathormone $(\mathrm{PTH})$ levels reach $50 \%$ of their initial values on the fourteenth day after renal $\mathrm{Tx}$ and that hyperparathyroidism (HPT) reverses during the first year after kidney Tx. However, elevated PTH levels have been observed in more than $25 \%$ of patients one year after renal Tx despite good renal function [6]. Besides persistent HPT, other factors have also been implicated in bone loss related to kidney Tx, such as immunosuppressive therapy, hypophosphataemia, hypomagnesaemia, and vitamin D deficiency [1].

The aim of the present study is to evaluate bone mineral density (BMD) in patients after renal $\mathrm{Tx}$ and associated factors to the development and persistence of bone disorder.

\section{Patients and Methods}

This was a cross-sectional study of patients submitted to kidney Tx and regularly seen as outpatients at the Clementino Fraga Filho Hospital, Federal University of Rio de Janeiro. The study was approved by the ethical committee and all participants signed an informed consent. Inclusion criteria were age $\geq 20$ years and glomerular filtration rate $\geq 60 \mathrm{~mL} / \mathrm{min} / 1.73 \mathrm{~m}^{2}$. Exclusion criteria were previous parathyroidectomy, return to dialysis, active diseases that could influence bone metabolism (such as systemic lupus, rheumatoid arthritis, celiac disease, diabetes mellitus, and AIDS), and use of any antiresorptive or anabolic drug (calcitonin, bisphosphonates, teriparatide, strontium ranelate, or denosumab) to treat bone disease in the last twelve months. The eighty-eight selected patients, 36 women and 52 men, had no limitations for physical activities, had no difficulty for walking, and were not receiving calcium and/or vitamin D. Patients received $0.5 \mathrm{mg} / \mathrm{Kg} / \mathrm{day}$ of prednisone until the third month after kidney $\mathrm{Tx}$ and then the dose was reduced to $5 \mathrm{mg} /$ day. Table 1 reports the daily pharmacological medication dosages at the time of the present evaluation. Forty-three received the kidney from living donors and forty-five from deceased donors. The cause of renal failure, time on dialysis, and time since transplantation were considered.

Body mass index (BMI) was estimated by the ratio weight $/$ height ${ }^{2}$ and expressed as $\mathrm{kg} / \mathrm{m}^{2}$. BMD was evaluated by dual-energy X-ray absorptiometry (DXA) using a Prodigy-GE densitometer and analyzed by the same experienced physician. BMD was measured at lumbar spine (LS), femoral neck (FN), and total femur (TF) and expressed in absolute values $(\mathrm{g} / \mathrm{cm} 2)$ and in standard deviations (SD) from peak bone mass ( $T$-score) and from expected BMD for agematched population ( $Z$-score). The reference standard from which $T$-score was calculated was the NHANES III and the Prodigy-GE densitometer databases, corrected for male sex when men were evaluated. In accordance with the World Health Organization and with the International Society of Clinical Densitometry (ISCD) official positions, the diagnosis of osteoporosis is based on a BMD $T$-score $\leq-2.5 \mathrm{SD}$ at any site of the skeleton of postmenopausal women and men aged 50 years and older. Values of $Z$-scores $\leq-2.0 \mathrm{SD}$ were considered lower than expected bone mass. The coefficient of variation $(\mathrm{CV})$ for the $\mathrm{BMD}$ measurements in normal subjects at our institution is $1.5 \%$ at LS and $2.3 \%$ at FN.

In the same day, blood was drawn after overnight fast for determination of serum calcium, phosphate, creatinine, and albumin by standard colorimetric methods. Calcium levels were corrected for albumin concentration, according to the formula: corrected calcium $(\mathrm{cCa})(\mathrm{mg} / \mathrm{dL})=$ serum calcium $(\mathrm{mg} / \mathrm{dL})+0.8 \times[4.0-$ serum albumin $(\mathrm{g} / \mathrm{dL})]$. Glomerular filtration rate was estimated by the formula of Cockcroft and Gault (values corrected for body surface area): [140 - age (years)] $\times$ weight $(\mathrm{Kg}) / 72 \times$ serum creatinine $(\mathrm{mg} / \mathrm{dL})$. For women, the result is multiplied by 0.85 . Serum samples were stored at $-80^{\circ} \mathrm{C}$ until analysis of intact PTH by chemiluminescent enzyme immunometric assay (kit DSL; Diagnostic Corp., California, USA; range 11-67 pg/mL); inter- and intraassay variations were $4.3 \%$ and $5.7 \%$, respectively; PTH analyses were run in duplicate.

\section{Statistical Analysis}

Statistical analysis was performed using SPSS 13.0 for Windows Student Version. Mann Whitney test compared groups: men and women, living and deceased donor, and patients with $Z$-score at any site $>-2.0 \mathrm{SD}$ versus $\leq-2.0 \mathrm{SD}$. Univariate Pearson or Kendall.s Tau_b. correlation coefficients were used to test the overall correlation between densitometric parameters and BMI, time on dialysis, time since kidney transplantation, calcium, phosphorus, creatinine, and PTH. Finally, a stepwise multiple regression analysis was used to investigate relationships between independent variables and $Z$-scores. All statistical tests were two-sided and $P$ values less than 0.05 were accepted as significant for all analyses in the study.

\section{Results}

Arterial hypertension was the main cause of renal failure (40\%) followed by undefined etiology (22\%), polycystic kidneys (7\%), glomerulonephritis (6\%), systemic lupus (4\%), 
TABLE 2: Comparisons between patients who received kidney transplant from living or deceased donors.

\begin{tabular}{|c|c|c|c|}
\hline & Living donor $(n=43)$ & Deceased donor $(n=45)$ & $P$ value \\
\hline \multicolumn{4}{|l|}{ Sex } \\
\hline Women & 16 & 20 & \\
\hline Men & 27 & 25 & 0.493 \\
\hline Age (years) & $40.1(31.3-46.7)$ & $49(39.6-54)$ & 0.004 \\
\hline BMI $\left(\mathrm{kg} / \mathrm{m}^{2}\right)$ & $23.6(22.3-26.5)$ & $25.5(22.7-28.3)$ & 0.176 \\
\hline Time on dialysis (months) & $20(12-48)$ & $90(62.5-108)$ & $<0.001$ \\
\hline Time since Tx (months) & $38(13-84)$ & $28(18-39)$ & 0.293 \\
\hline cCalcium (mg/dL) & $9.2(8.9-9.7)$ & $9.5(9.1-9.8)$ & 0.343 \\
\hline Phosphorus (mg/dL) & $2.9(2.7-3.3)$ & $3(2.6-3.5)$ & 0.627 \\
\hline Creatinine (mg/dL) & $1.1(1.3-1.7)$ & $1.2(1.1-1.5)$ & 0.261 \\
\hline Albumin (g/dL) & $4.3(4.2-4.6)$ & $4.3(4.1-4.6)$ & 0.839 \\
\hline PTH (pg/mL) & $47.3(37.6-72.7)$ & $72.7(38.7-126)$ & 0.126 \\
\hline Lumbar spine $Z$-score & $-1.3(-1.9-0.1)$ & $-0.7(-1.5-0.2)$ & 0.251 \\
\hline Femoral neck $Z$-score & $-0.8(-1.3-0.2)$ & $-0.6(-1.3-0.1)$ & 0.726 \\
\hline Total femur $Z$-score & $-0.6(-1.4-0)$ & $-0.8(-1.4--0.1)$ & 0.917 \\
\hline
\end{tabular}

BMI: body mass index; Tx: transplant; cCalcium (corrected for albumin); PTH: parathormone. Results in absolute numbers or median (interquartile interval).

obstructive uropathy (3\%), IgA nephropathy (2\%), druginduced nephropathy $(2 \%)$, virus B hepatitis $(1 \%)$, and leptospirosis (1\%).

Results are expressed as median values (interquartiles interval). Consider the whole population: age (years) 44.3 (37.2-52.5), time on dialysis (months) 60 (12-91.3), and time elapsed from transplantation to the study (months) 31.5 (15.8$62.5)$. The only sex difference was serum creatinine $(\mathrm{mg} / \mathrm{dL})$, higher in male, 1.4 (1.2-1.7), than in female patients, 1.1 (11.4), $P<0.001$. Patients who received kidney transplant from living donors were younger and remained less time on dialysis. Comparisons are shown in Table 2. No patients had graft rejection.

Serum PTH was above normal levels in $42 \%$ of all patients, and cCalcium was normal in all but five patients (mildly hypercalcemic). However, median (quartile interval) of cCalcium, phosphorus, glomerular filtration rate, time on dialysis, and time since transplantation did not differ between patients with high or normal PTH. The only difference was a lower median LS $Z$-score $(-1.6 \mathrm{SD})$ in patients with hyperparathyroidism compared to subjects with normal PTH values $(-0.8 \mathrm{SD} ; P<0.05)$.

No patient reported fragility fracture. Bone density $T$ score at lumbar spine and/or proximal femur was $\leq-2.5 \mathrm{SD}$ in three of the twelve postmenopausal women and in five of the 17 men aged fifty years and older (age range $52-66.5$ years, median 53.4 years). Thus, prevalence of osteoporosis in these patients was $27.6 \%$. BMI tended to be lower in osteoporotic patients $(P=0.089)$.

Considering the whole group, twenty-five patients (28.4\%) had a bone density $Z$-score $\leq-2.0 \mathrm{SD}$ at lumbar spine and/or proximal femur. The only difference between these patients and those with a $Z$-score $<-2 \mathrm{SD}$ was serum PTH, higher in the former. These data are shown in Table 3.

The significant correlations identified after stepwise multiple regression analysis are shown in Table 4. An inverse correlation between serum PTH and Z-score at LS, FN, and TF

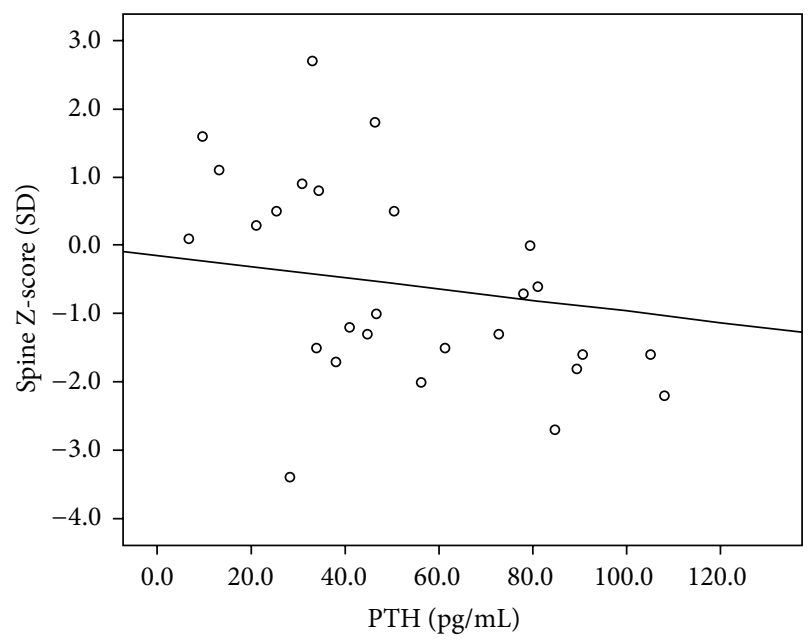

FIGURE 1: Correlation between serum PTH levels and lumbar spine $Z$-score in women $\left(r^{2}=0.442, P<0.001\right)$. PTH: parathormone; $\mathrm{SD}$ : standard deviation.

was statistically significant only in women. Figure 1 illustrates this inverse correlation at LS.

\section{Discussion}

The determinants of chronic renal disease in this study were similar to previously reported ones, because hypertension is the leading cause of ESRD in Brazil. Interestingly, the diagnosis of diabetes mellitus was not included as a cause of ESRD in this group, but probably it may corresponded to part of the undefined causes of chronic renal disease. Men and women did not differ in demographics and biochemical and densitometric parameters. The only exception was serum creatinine, higher in men but always compatible with a glomerular filtration rate $\geq 60 \mathrm{~mL} / \mathrm{min} / 1.73 \mathrm{~m}^{2}$, possibly due to a 
TABLE 3: Comparisons between patients with bone density $Z$-scores $\leq-2.0 \mathrm{SD}$ at lumbar spine and/or proximal femur.

\begin{tabular}{|c|c|c|c|}
\hline & $Z$-score $\leq-2.0 \mathrm{SD}(n=25)$ & $Z$-score $>-2.0 \mathrm{SD}(n=63)$ & $P$ value \\
\hline \multicolumn{4}{|l|}{ Sex } \\
\hline Women & 8 & 28 & 0.287 \\
\hline Men & 17 & 35 & \\
\hline Age (years) & $44.5(34.6-52)$ & $43.7(37.4-53.9)$ & 0.691 \\
\hline $\operatorname{BMI}\left(\mathrm{kg} / \mathrm{m}^{2}\right)$ & $24.6(19.7-28.3)$ & $24.9(22.8-26.7)$ & 0.307 \\
\hline Time on dialysis (months) & $78(12-84)$ & $60(13-96)$ & 0.880 \\
\hline Time since Tx (months) & $29(14-48)$ & $32(17.5-68.5)$ & 0.598 \\
\hline \multicolumn{4}{|l|}{ Donor } \\
\hline Living & 14 & 29 & 0.402 \\
\hline Deceased & 11 & 34 & \\
\hline cCalcium (mg/dL) & $9.4(9-9.8)$ & $9.3(8.9-9.7)$ & 0.506 \\
\hline Phosphorus (mg/dL) & $3(2.8-3.2)$ & $3(2.6-3.6)$ & 0.858 \\
\hline Creatinine (mg/dL) & $1.4(1.1-1.6)$ & $1.2(1.1-1.6)$ & 0.552 \\
\hline Albumin $(\mathrm{g} / \mathrm{dL})$ & $4.4(4.3-4.6)$ & $4.3(4.1-4.6)$ & 0.104 \\
\hline PTH (pg/dL) & $83.3(49.1-137.8)$ & $48.2(33.1-79.3)$ & 0.016 \\
\hline
\end{tabular}

BMI: body mass index; Tx: transplant; cCalcium (corrected for albumin); PTH: parathormone. Data expressed as absolute values or median (interquartile interval).

TABLe 4: Correlations between bone density $Z$-scores and age, body mass index (BMI), PTH, time on dialysis, and time from kidney transplantation to bone mineral density evaluation (Tx-BMD) in different subgroups populations.

\begin{tabular}{|c|c|c|c|}
\hline Groups/sites & $\begin{array}{l}\text { Lumbar spine } \\
Z \text {-score }\end{array}$ & $\begin{array}{c}\text { Femoral neck } \\
Z \text {-score }\end{array}$ & $\begin{array}{l}\text { Total femur } \\
Z \text {-score }\end{array}$ \\
\hline All patients & No correlation & No correlation & No correlation \\
\hline Men & No correlation & No correlation & No correlation \\
\hline Women & $\begin{array}{c}\text { PTH and age } \\
\left(r^{2}=0.442 P<0.001\right)\end{array}$ & $\begin{array}{c}\text { PTH } \\
\left(r^{2}=0.356 P<0.001\right)\end{array}$ & $\begin{array}{c}\text { PTH } \\
\left(r^{2}=0.347 P<0.001\right)\end{array}$ \\
\hline Deceased donor & $\begin{array}{c}\text { Time on dialysis } \\
\left(r^{2}=0.118 P=0.034\right)\end{array}$ & No correlation & $\begin{array}{c}\text { Time TPX-BMD } \\
\left(r^{2}=0.172 P=0.010\right)\end{array}$ \\
\hline Living donor & $\begin{array}{c}\text { Time on dialysis } \\
\left(r^{2}=0.167 P=0.038\right)\end{array}$ & $\begin{array}{c}\text { Time on dialysis } \\
\left(r^{2}=0.270 P=0.007\right)\end{array}$ & $\begin{array}{l}\text { Time on dialysis and BMI } \\
\quad\left(r^{2}=0.412 P=0.002\right)\end{array}$ \\
\hline
\end{tabular}

Dependent variable: bone mineral density $Z$-scores.

Independent variables: sex, age, BMI, time on dialysis, time Tx-BMD, type of kidney donor, PTH, calcium, phosphorus, creatinine, and albumin.

greater muscle mass in males. Thus, a homogeneous group was evaluated, despite the different etiologies of ESRD.

As expected, older patients had lower BMD, since aging is related to bone loss. Data obtained from patients between 6 and 20 years after renal Tx (when bone loss is in a stable period) showed a mean annual decrease in lumbar $T$-scores of $-0.6 \pm 1.9 \%$, a value similar to the observed decline in the general population with aging [7]. So, together, both conditions may predispose to a greater bone loss.

Among the general population, higher BMI have been shown to be protective against osteoporosis [8]. Sezer et al. reported lower post-Tx BMI in osteoporotic compared to osteopenic or normal subjects [9] and another recent trial revealed BMI to be an independent risk factor for a lower $T$-score at femoral neck [10]. A negative correlation between $\mathrm{BMI}$ and BMD was also reported in our group.

Longer time on dialysis is generally associated with longer time under the deleterious effects of uremia and secondary HPT. There seems to be no doubt that pre-Tx CKD-MBD plays an important role in the maintenance or development of post-Tx alterations of bone remodeling [11]. Thereby, our findings showed that longer time on dialysis is related to lower
BMD after renal Tx and corroborates the importance of preTx bone disease.

Even though patients who received kidney Tx from living donors were younger and remained less time on dialysis, no differences were found in other data, including BMD $(Z$ score). Therefore, donor source did not affect the current bone health of these individuals.

Metabolic bone disease after kidney transplantation has a complex pathophysiology and heterogeneous histology. Bone density loss remains a serious problem after renal $\mathrm{Tx}$ and is most pronounced during the first months of engraftment. Each patient may have multiple risk factors for bone loss, such as steroids usage, hypogonadism, persistent hyperparathyroidism, poor allograft function, metabolic acidosis, hypophosphatemia, vitamin D deficiency, aging, immobility, and chronic disease. The main alterations in bone remodeling after renal Tx probably consist of a decrease in bone formation and mineralization in the face of persistent bone resorption [11]. Almost all studies noticed a BMD loss at lumbar spine, if no bone sparing medication was used. In the first six months, median bone loss was $4.1 \%$ and persisted in the majority of cases at one year after engraftment, although 
at a lower level (median 3.4\%). At the femoral neck, bone loss was slightly less after six months (median 2.8\%) but showed a tendency to increase further thereafter [12]. Controversial data exist concerning BMD development in long-term kidney transplant recipients. While some studies demonstrated no further significant bone loss after the first post-Tx year [13, 14 ], another study noticed an ongoing reduction in lumbar spine $\mathrm{BMD}$ of $1.7 \%$ per year [15]. On the other hand, a study found BMD stabilization beyond the second post-Tx year, followed by an improvement of 1-2\% per year thereafter [16]. Our patients presented a median time elapsed from Tx to the study above 2 years ( 31.5 months), suggesting they already had most of their bone loss related to post-Tx period. The clinical impact of post-Tx osteopathy and bone loss is a marked increase in the fracture rate following kidney $\mathrm{Tx}$, almost threefold higher in patients after renal Tx compared to subjects in hemodialysis [17]. When comparing to healthy controls, the rise in fracture incidence varies between fivefold and 34-fold, depending on sex and age of kidney recipients [18].

Posttransplantation immunosuppressive treatment may have a major impact on the pathogenesis of bone disease. Corticosteroids can be directly toxic to osteoblasts and lead to increased osteoclast activity [19]. During the first months after Tx, rapid bone loss secondary to steroid-induced acceleration in bone remodeling occurs. Steroids withdrawal three months after kidney Tx was associated with decreased risk of osteoporosis $[20,21]$ and steroid withdrawal one year after kidney Tx was associated with improved BMD [22]. None of our patients were receiving corticosteroids in high doses ( $>5 \mathrm{mg} /$ day of prednisone), which could be related to bone loss. Moreover, our patients were using only mycophenolate mofetil and tacrolimus as posttransplantation immunosuppressive treatment and these medications do not affect BMD [19, 23].

Persistent HPT is a frequent finding in kidney graft recipients [24]. Torres et al. showed that only $23 \%$ of long-term recipients with serum creatinine below $2 \mathrm{mg} / \mathrm{dL}$ had PTH levels within the normal range [25]. We found $42 \%$ of the evaluated patients with elevated PTH levels, even though all of them had glomerular filtration rate $\geq 60 \mathrm{~mL} / \mathrm{min} / 1.73 \mathrm{~m}^{2}$. The most important risk factors for ongoing hyperparathyroidism are dialysis duration, severity of secondary HPT prior to $\mathrm{Tx}$, and development of monoclonal hyperplasia of the parathyroid glands (tertiary HPT) [26]. In five of our patients $(5.7 \%)$, corrected calcium was elevated, suggesting autonomous or tertiary HPT. In the remaining patients with elevated serum PTH, corrected calcium was normal, suggesting secondary HPT. Additional factors that may contribute to elevated PTH levels are hypovitaminosis D and decreased calcium absorption caused by corticosteroids [3]. Many studies related persistent HPT to increased bone turnover and decreased BMD after Tx. In our trial, PTH levels were significantly higher in the twenty-four patients with lower than expected bone mass $(Z$-score $\leq-2.0 \mathrm{SD}$ in lumbar spine and/or proximal femur) compared with the sixty-four patients with normal $Z$-score, suggesting the involvement of PTH in the reduction of BMD. In the female group (36 patients), the inverse correlation between PTH and $Z$-score confirmed this finding. Other authors also demonstrated similar results $[19,27,28]$, highlighting the role of PTH in bone loss after renal Tx.

Organ transplantation is now a well-known condition associated with secondary osteoporosis. Current guidelines for bone disease in renal Tx recommend that patients should be regularly monitored for changes in their bone mass. BMD measurements by DXA scans should be obtained at the time of Tx as well as 1 and 2 years thereafter [29]. We observed a high prevalence of osteoporosis in postmenopausal women (25\%) and in men aged fifty years and older (29.4\%), with an overall prevalence of $27.6 \%$. Patel et al. found a similar prevalence of osteoporosis in 165 transplant patients, ranging from 10 to $44 \%$ and depending on gender or measured site [30]. Although our patients did not report fragility fractures, we cannot exclude the prevalence of asymptomatic fractures (mainly vertebral ones), which could lead to even greater prevalence of osteoporosis in these patients. A cross-sectional study demonstrated an osteoporotic fracture prevalence of $17 \%$ in renal Tx recipients. A higher rate was found among recipients with diabetes type $1(40 \%)$ and among females (23\%) [31]. Thus, further studies evaluating vertebrae morphometry by X-ray or by DXA scans (vertebral fracture assessment or VFA) should be performed in order to clarify the real prevalence of asymptomatic vertebral fractures in this population, which indicates the need for pharmacological treatment.

Our study has some limitations. First, the transversal design prevented the evaluation of BMD pre-Tx and the rate of bone loss after engraftment. Timing of the DXA scans was variable (13-84 months) but all patients went through the worst period for bone heath, which is the first year after kidney Tx $[11,12]$. Other limitations were the small size of the sample and the lack of data about other factors that may affect $\mathrm{BMD}$, like $25(\mathrm{OH})$ vitamin $\mathrm{D}$, which could be responsible for the elevation of PTH levels seen in some subjects.

Bone disease related to renal $\mathrm{Tx}$ is a common disorder and is associated with higher morbidity and mortality. Our study highlights older age, lower BMI, longer time on dialysis, and persistent HPT as important risk factors for this condition. Adequate screening, correction of modifiable predisposing conditions, and treatment of bone loss are essential for proper management of these patients, leading to longer survival and improved quality of life.

\section{Conclusions}

A high prevalence of bone involvement after renal Tx was observed in this study and the main influences on the reduction of BMD were age, BMI, dialysis duration, and $\mathrm{PTH}$ levels.

\section{Conflict of Interests}

The authors have declared that no conflict of interest exists. 


\section{References}

[1] H. Sadideen, A. Covic, and D. Goldsmith, "Mineral and bone disorder after renal transplantation: a review," International Urology and Nephrology, vol. 40, no. 1, pp. 171-184, 2008.

[2] A. Cohen and E. Shane, "Osteoporosis after solid organ and bone marrow transplantation," Osteoporosis International, vol. 14, no. 8, pp. 617-630, 2003.

[3] C. Mitterbauer and R. Oberbauer, "Bone disease after kidney transplantation," Transplant International, vol. 21, no. 7, pp. 615624, 2008.

[4] P. R. Ebeling, "Approach to the patient with transplantationrelated bone loss," Journal of Clinical Endocrinology and Metabolism, vol. 94, no. 5, pp. 1483-1490, 2009.

[5] A. Cohen, P. Sambrook, and E. Shane, "Management of bone loss after organ transplantation," Journal of Bone and Mineral Research, vol. 19, no. 12, pp. 1919-1932, 2004.

[6] W. Reinhardt, H. Bartelworth, F. Jockenhövel et al., "Sequential changes of biochemical bone parameters after kidney transplantation," Nephrology Dialysis Transplantation, vol. 13, no. 2, pp. 436-442, 1998.

[7] V. M. Brandenburg, M. Ketteler, N. Heussen et al., "Lumbar bone mineral density in very long-term renal transplant recipients: impact of circulating sex hormones," Osteoporosis International, vol. 16, no. 12, pp. 1611-1620, 2005.

[8] M. Pirro, G. Fabbriciani, C. Leli et al., "High weight or body mass index increase the risk of vertebral fractures in postmenopausal osteoporotic women," Journal of Bone and Mineral Metabolism, vol. 28, no. 1, pp. 88-93, 2010.

[9] S. Sezer, F. N. Ozdemir, A. Ibis, B. Sayin, and M. Haberal, "Risk factors for osteoporosis in young renal transplant recipients," Transplantation Proceedings, vol. 37, no. 7, pp. 3116-3118, 2005.

[10] A. Unal, I. Kocyigit, M. H. Sipahioglu et al., "Loss of bone mineral density in renal transplantation recipients," Transplantation Proceedings, vol. 42, no. 9, pp. 3550-3553, 2010.

[11] J. R. Weisinger, R. G. Carlini, E. Rojas, and E. Bellorin-Font, "Bone disease after renal transplantation," Clinical Journal of the American Society of Nephrology, vol. 1, no. 6, pp. 1300-1313, 2006.

[12] K. Kodras and M. Haas, "Effect of kidney transplantation on bone," European Journal of Clinical Investigation, vol. 36, no. 2, pp. 63-75, 2006.

[13] V. M. Brandenburg, M. Ketteler, W. J. Fassbender et al., "Development of lumbar bone mineral density in the late course after kidney transplantation," American Journal of Kidney Diseases, vol. 40, no. 5, pp. 1066-1074, 2002.

[14] V. M. Brandenburg, D. Politt, M. Ketteler et al., "Early rapid loss followed by long-term consolidation characterizes the development of lumbar bone mineral density after kidney transplantation," Transplantation, vol. 77, no. 10, pp. 1566-1571, 2004.

[15] V. Pichette, A. Bonnardeaux, L. Prudhomme, M. Gagné, J. Cardinal, and D. Ouimet, "Long-term bone loss in kidney transplant recipients: a cross-sectional and longitudinal study," American Journal of Kidney Diseases, vol. 28, no. 1, pp. 105-114, 1996.

[16] W. H. Grotz, F. A. Mundinger, J. Rasenack et al., "Bone loss after kidney transplantation: a longitudinal study in 115 graft recipients," Nephrology Dialysis Transplantation, vol. 10, no. 11, pp. 2096-2100, 1995.

[17] W. H. Grotz, F. A. Mundinger, B. Gugel, V. Exner, G. Kirste, and P. J. Schollmeyer, "Bone fracture and osteodensitometry with dual energy $\mathrm{x}$-ray absorptiometry in kidney transplant recipients," Transplantation, vol. 58, no. 8, pp. 912-915, 1994.

[18] R. Ramsey-Goldman, J. E. Dunn, D. D. Dunlop et al., "Increased risk of fracture in patients receiving solid organ transplants," Journal of Bone and Mineral Research, vol. 14, no. 3, pp. 456$463,1999$.

[19] K. Kalantar-Zadeh, M. Z. Molnar, C. P. Kovesdy, I. Mucsi, and S. Bunnapradist, "Management of mineral and bone disorder after kidney transplantation," Current Opinion in Nephrology and Hypertension, vol. 21, no. 4, pp. 389-403, 2012.

[20] H. M. Alshayeb, M. A. Josephson, and S. M. Sprague, "CKDmineral and bone disorder management in kidney transplant recipients," The American Journal of Kidney Diseases, vol. 61, no. 2, pp. 310-325, 2013.

[21] M. Hazzan, F. Glowacki, A. Lionet, F. Provôt, and C. Noël, "Weaning from corticosteroid therapy after kidney transplantation," Nephrologie et Therapeutique, vol. 5, supplement 6, pp. S355-S358, 2009.

[22] S. W. Ing, L. T. Sinnott, S. Donepudi, E. A. Davies, R. P. Pelletier, and N. E. Lane, "Change in bone mineral density at one year following glucocorticoid withdrawal in kidney transplant recipients," Clinical Transplantation, vol. 25, no. 2, pp. E113E123, 2011.

[23] A. K. Gupta, M. Huang, and G. V. Ramesh Prasad, "Determinants of bone mineral density in stable kidney transplant recipients," Journal of Nephrology, vol. 25, no. 3, pp. 373-383, 2012.

[24] B. A. Julian, L. D. Quarles, and K. M. W. Niemann, "Musculoskeletal complications after renal transplantation: pathogenesis and treatment," The American Journal of Kidney Diseases, vol. 19, no. 2, pp. 99-120, 1992.

[25] A. Torres, A. P. Rodríguez, M. T. Concepción et al., "Parathyroid function in long-term renal transplant patients: importance of pre-transplant PTH concentrations," Nephrology Dialysis Transplantation, vol. 13, supplement 3, pp. 94-97, 1998.

[26] P. C. Koch Nogueira, L. David, and P. Cochat, "Evolution of secondary hyperparathyroidism after renal transplantation," Pediatric Nephrology, vol. 14, no. 4, pp. 342-346, 2000.

[27] J. V. Torregrosa, J. M. Campistol, M. Montesinos, F. Pons, and M. J. Martinez de Osaba, "Evolution of bone mineral density after renal transplantation: related factors," Nephrology Dialysis Transplantation, vol. 10, supplement 6, pp. 111-113, 1995.

[28] J. G. Heaf, E. Tvedegaard, I. L. Kanstrup, and N. Fogh-Andersen, "Hyperparathyroidism and long-term bone loss after renal transplantation," Clinical Transplantation, vol. 17, no. 3, pp. 268 274, 2003.

[29] National Kidney Foundation, "K/DOQI clinical practice guidelines for bone metabolism and disease in chronic kidney disease," Am J Kidney Dis, vol. 42, pp. S1-S201, 2003.

[30] S. Patel, J. T. C. Kwan, E. McCloskey et al., "Prevalence and causes of low bone density and fractures in kidney transplant patients," Journal of Bone and Mineral Research, vol. 16, no. 10, pp. 1863-1870, 2001.

[31] U. Nisbeth, E. Lindh, S. Ljunghall, U. Backman, and B. Fellström, "Increased fracture rate in diabetes mellitus and females after renal transplantation," Transplantation, vol. 67, no. 9, pp. $1218-1222,1999$. 


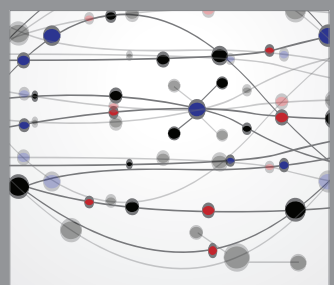

The Scientific World Journal
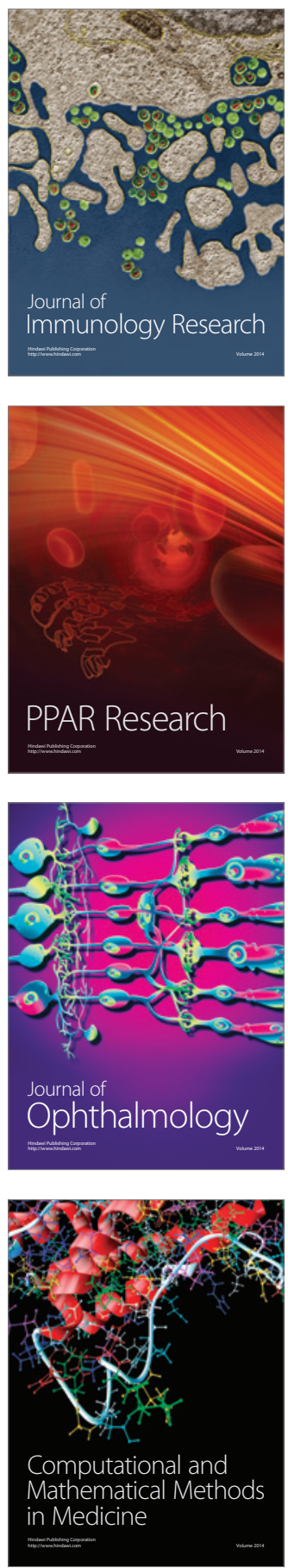

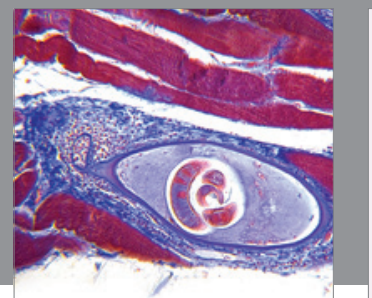

Gastroenterology

Research and Practice
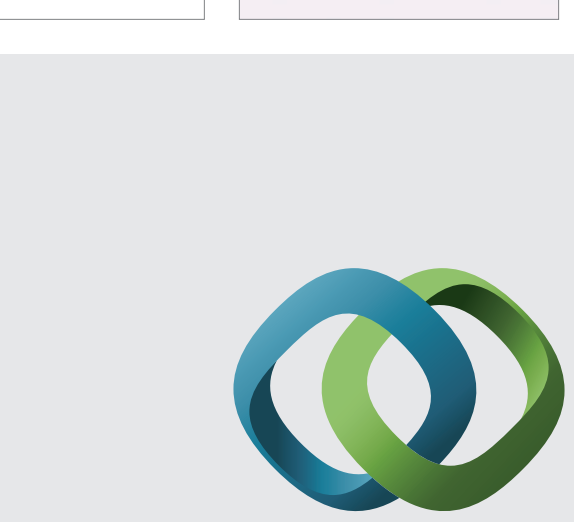

\section{Hindawi}

Submit your manuscripts at

http://www.hindawi.com
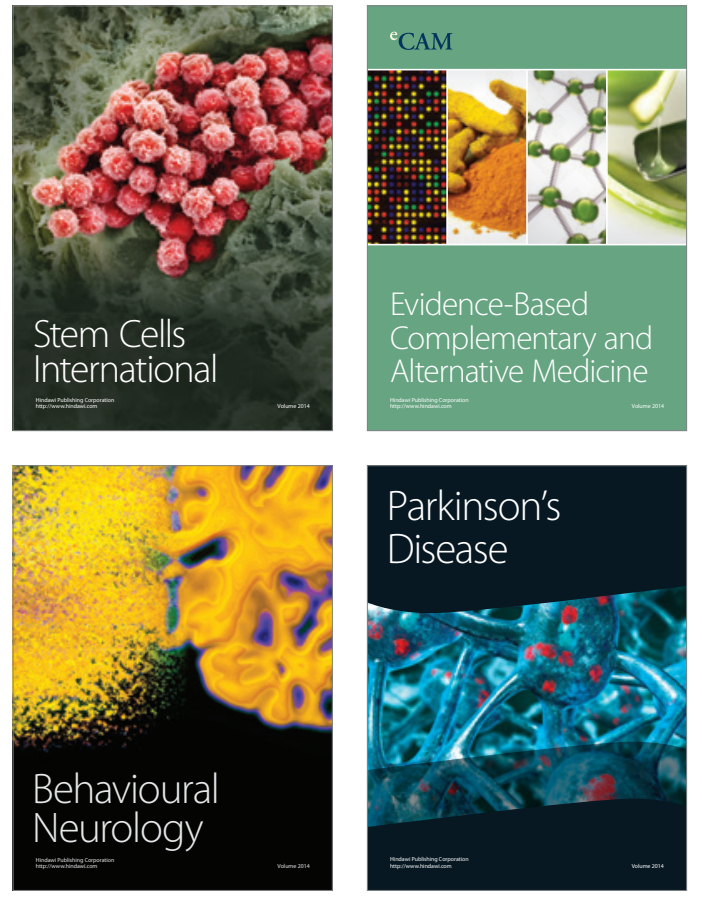
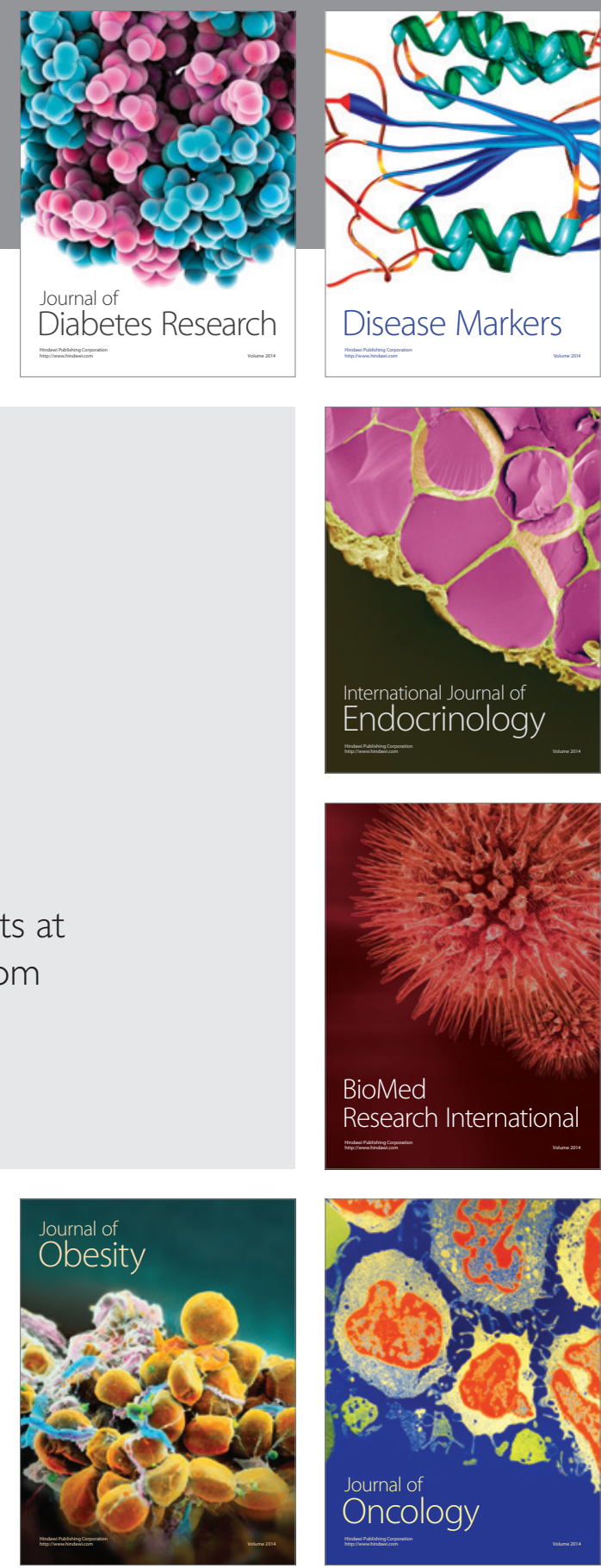

Disease Markers
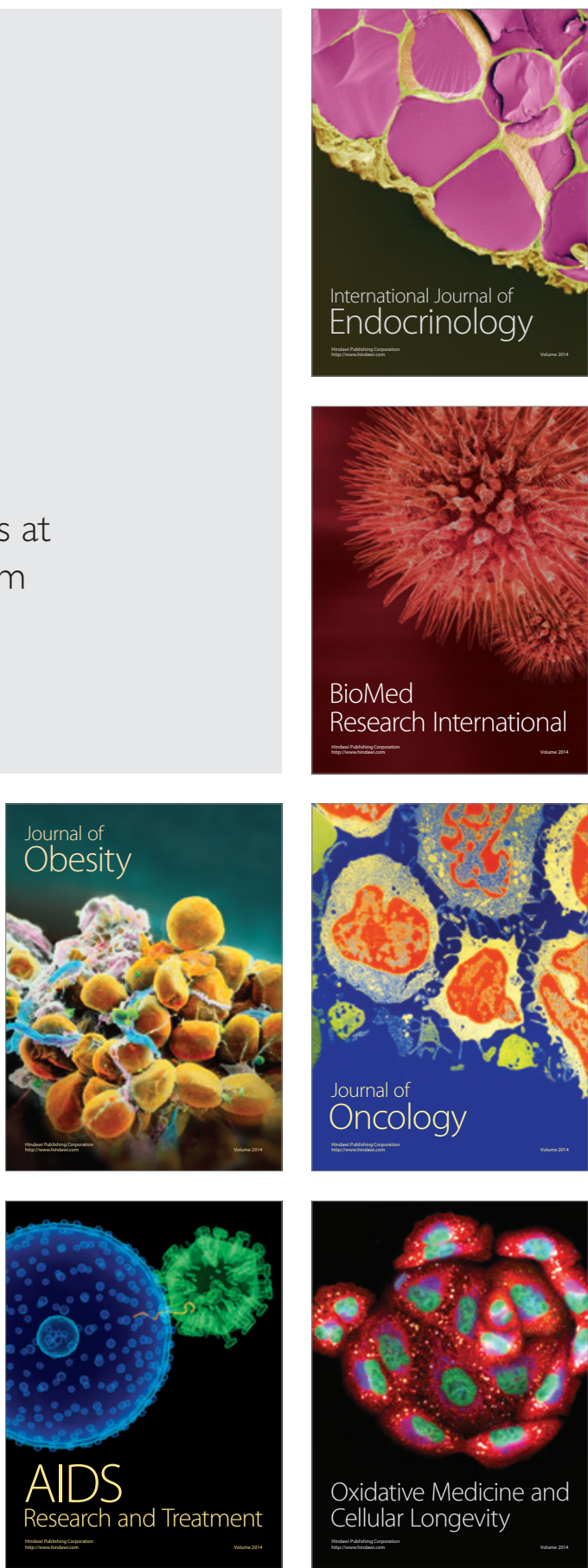